\title{
Association Study of MTHFR Polymorphisms with Nonarteritic Anterior Ischemic Optic Neuropathy in a Spanish Population
}

\author{
Beatriz Fernández-Vega ${ }^{a-c} \quad$ Lydia Álvarez $^{b} \quad$ Montserrat García ${ }^{a}$ b \\ Enol Artime ${ }^{b}$ Marta Diñeiro Soto ${ }^{d}$ Javier Nicieza ${ }^{e} \quad$ José A. Vega ${ }^{c} f$ \\ Héctor González-Iglesiasa, b \\ ${ }^{a}$ Instituto Oftalmológico Fernández-Vega, Oviedo, Spain; ${ }^{b}$ Instituto Universitario \\ Fernández-Vega, Fundación de Investigación Oftalmológica, Universidad de Oviedo, \\ Oviedo, Spain; ' Departamento de Morfología y Biología Celular, Grupo SINPOS, \\ Universidad de Oviedo, Oviedo, Spain; ${ }^{\mathrm{d} I n s t i t u t o}$ de Medicina Oncológica y Molecular \\ de Asturias (IMOMA), Oviedo, Spain; ${ }^{\mathrm{e} H o s p i t a l ~ d e ~ C a b u e n ̃ e s, ~ G i j o ́ n, ~ S p a i n ; ~}{ }^{\mathrm{f}} \mathrm{Facultad}$ de \\ Ciencias de la Salud, Universidad Autónoma de Chile, Santiago de Chile, Chile
}

\section{What Is It About?}

The methylenetetrahydrofolate reductase (MTHFR) genetic polymorphisms C677T and A1298C lead to the synthesis of a thermolabile enzyme, which may act as a risk factor of nonarteritic anterior ischemic optic neuropathy (NAION). An association study of the MTHFR polymorphisms with NAION was carried out in 94 unrelated NAION patients and 204 healthy controls. Although the prevalence of the MTHFR risk variants was higher in our population, not significant differences were observed when comparing NAION patients and controls, and therefore additional risk factors are contributing to the onset of the disease.

\section{Keywords}

Nonarteritic anterior ischemic optic neuropathy - Methylenetetrahydrofolate reductase gene * Association study · C677T · A1298C

\section{Abstract}

Introduction: Nonarteritic anterior ischemic optic neuropathy (NAION), painless loss of central and/or peripheral vision, is a multifactorial disease caused by insufficient blood flow through the posterior ciliary arteries to the optic nerve head. Mutations in the methylenetetrahydrofolate reductase (MTHFR) gene, triggering hyperhomocysteinemia as a consequence of a decreased activity of the codified enzyme, have been considered to be among the risk factors of NAION. Objective: The main aim was to study the association of the most common 
MTHFR genetic polymorphisms C677T and A1298C with NAION in a Spanish population. Methods: In this case-control study, the association of the most common MTHFR polymorphisms was investigated in 94 unrelated native Spanish patients diagnosed with NAION and 204 healthy controls. Two single nucleotide polymorphisms located in the MTHFR gene, C677T (rs1801133) and A1298C (rs1801131), were analyzed by DNA sequencing and TaqMan assays. Results: The allelic and genotypic frequencies of the MTHFR variants obtained in the NAION group were not significantly different when compared with the control group. A higher frequency of the C677T/A1298C genotype, codifying the nonmutated MTHFR form, was obtained in control subjects (11.27\%) compared to NAION patients (4.26\%), suggesting a protective effect of the wild-type protein, although this result was not conclusive considering the obtained confidence interval $(\mathrm{Cl})(95 \% \mathrm{Cl}$ : 0.13-1.06). Study of additional clinical factors including hypertension, diabetes mellitus, and dyslipidemia showed no association with a higher risk of NAION. Conversely, the clinical history of heart or cerebrovascular diseases was significantly higher in NAION patients compared to controls. Over the world, risk variants of the MTHFR gene are highly frequent, excluding African black populations, indicating a racial influence. Conclusions: The MTHFR variants did not significantly increase the risk of suffering from NAION. However, considering that individuals with at least one of the risk variants have the MTHFR enzyme with decreased activity, it cannot be ruled out that these mutations are relevant for the development of NAION in a subgroup of the population with other specific characteristics. These may include high plasma levels of homocysteine along with nutritional deficiencies including low folate or vitamin B12 and the combination of systemic and local risk factors.

(C) 2020 The Author(s)

Published by S. Karger AG, Basel

\section{Introduction}

Ischemic optic neuropathy is a sudden loss of central and/or peripheral vision due to a decrease or interruption of blood flow to the optic nerve. It is not a single disease but a spectrum of ocular diseases characterized by the ischemic nature of the lesion in the optic nerve [1]. There are two types of ischemic optic neuropathy, depending on the region of the optic nerve affected: anterior ischemic optic neuropathy (AION), which is due to an interruption or an insufficiency in the blood flow to the optic nerve head (ONH) supplied by the posterior ciliary arteries (PCAs) [2], and posterior ischemic optic neuropathy, as a result of ischemia in the posterior part of the optic nerve [3].

Among AION cases, the most common ischemic optic neuropathy in adults, we can distinguish between arteritic AION and nonarteritic AION (NAION) [4]. Arteritic AION is a dangerous condition caused by inflammation of the arteries supplying blood to the optic nerve. The inflammation is mainly associated with a systemic disorder known as giant cell arteritis. NAION is the most common form of AION, where no inflammation of the arteries occurs, and may result in severe visual acuity or visual field loss [5]. NAION typically presents as acute, unilateral, and painless loss of central and/or peripheral vision that may progress over several hours or days. NAION mainly affects patients over 50 years of age, but the neuropathy may appear at any age, and both men and women have the same rates of occurrence $[6,7]$.

Even though the pathogenesis of NAION is unclear, it is considered a multifactorial disease in which a variety of systemic and ocular risk factors play a role. Systemic risk factors include diabetes mellitus (DM) [8-15], nocturnal arterial hypotension [16, 17], arterial hypertension $[8,11,13,15,18]$, hypercholesterolemia and ischemic heart disease $[10,12,13,15$, $18,19]$, blood loss [20], atherosclerosis [8], sleep apnea syndrome [21-25], cardiovascular 
Fernández-Vega et al.: MTHFR Polymorphisms and Nonarteritic Anterior Ischemic Optic Neuropathy

disorders [8, 15], migraine [21], and erectile dysfunction drugs such as sildenafil [26-28]. Ocular risk factors include a small and crowded disc [15, 29], elevated intraocular pressure, or optic disc drusen that may influence the ONH blood supply [30].

It is widely accepted that sleep-induced nocturnal arterial hypotension, sometimes aggravated by antihypertensive therapy, is an important factor in the pathogenesis of NAION. A fall in blood pressure, along with other underlying risk factors, could cause insufficient blood flow through the PCAs to the ONH. This hypothesis is based on the observation that the first symptoms of NAION are usually noticed after nighttime sleep or after a nap, when a physiological drop in blood pressure occurs [16, 17, 31-34].

Great controversy exists in relation to the association of thrombophilic risk factors with NAION. While some authors point to an association between some of these factors and the disease [11, 19, 35-41], others have not found such a relationship [9, 42]. Hyperhomocysteinemia is an important thrombophilic marker associated with an increased risk of coronary heart disease [43]. Several studies have found an association between hyperhomocysteinemia and NAION $[11,18,39,44]$. Insufficient intake of vitamin B12, vitamin B6, and folic acid as well as a genetic predisposition are among the factors contributing to elevated plasma homocysteine levels. Specifically, mutations in the gene encoding the protein methylenetetrahydrofolate reductase (MTHFR) are the most commonly known genetic risk factor for hyperhomocysteinemia. The MTHFR protein is an important enzyme in the homocysteine metabolism, which catalyzes the conversion of 5,10-methylenetetrahydrofolate into 5-methyltetrahydrofolate [45]. The most common MTHFR mutations are two single nucleotide polymorphisms (SNPs), C677T and A1298C. Both SNPs result in a decreased MTHFR activity, more pronounced for MTHFR C677T, which may lead to hyperhomocysteinemia mainly in the presence of low plasma folate levels [45-47]. Individuals with the genotype 677TT have approximately only $30 \%$ of MTHFR enzyme activity, whereas heterozygotes $677 \mathrm{CT}$ have around $65 \%$ of enzymatic activity [48].

To date, only six studies addressing the association of the MTHFR C677T variant with NAION have been published, obtaining controversial results. Two of them, performed in a population from Italy [40] and in a population from the USA [36], observed a significant association of the 677TT genotype with the disease ( $p=0.005$ and $p=0.004$, respectively). However, those carried out in populations from Italy [18], the USA [41], Austria [11], and Israel [10] did not find evidence of higher risk of NAION in patients with this genotype. Regarding the MTHFR A1298C polymorphism, Felekis et al. [40] did not find a significant association with NAION in an Italian population.

Considering that there is no effective treatment for NAION, the study of potential genetic risk factors could help elucidate the pathogenesis of the disease in certain groups of patients and determine the suitability of complementary genetic tests for clinical management. Through this case-control study we aimed to investigate the association of the MTHFR variants C677T and A1298C with NAION in a Spanish population of 298 subjects (cases and controls).

\section{Materials and Methods}

\section{Study Subjects}

A total of 94 unrelated native Spanish patients diagnosed with NAION and 204 healthy controls recruited at Fernández-Vega Ophthalmological Institute, Oviedo, Spain were included in the present case-control study. Control subjects were selected from patients undergoing cataract surgery without history or clinical evidence of ischemic optic neuropathy. Complete ophthalmic examinations were performed for both patients and controls, who were also subjected to a detailed interview aimed at collecting the presence of risk factors, including 
Fernández-Vega et al.: MTHFR Polymorphisms and Nonarteritic Anterior Ischemic Optic Neuropathy

Table 1. Demographic characteristics of the recruited NAION patients and control subjects

\begin{tabular}{lllr}
\hline & NAION patients $(n=94)$ & Controls $(n=204)$ & $p$ value \\
\hline Men/women & $48(51.06 \%) / 46(48.94 \%)$ & $84(41.18 \%) / 120(58.82 \%)$ & 0.1103 \\
Age, years & $57.39^{\mathrm{a}} \pm 16.54$ & $65.48 \pm 11.32$ & $<0.0001$ \\
Age range, years & $18-87$ & $35-91$ & \\
\hline
\end{tabular}

Values are presented as $n(\%)$, mean \pm standard deviation, or range. NAION, nonarteritic anterior ischemic optic neuropathy. ${ }^{\text {a }}$ Average age at the first event.

Table 2. Demographic and clinical characteristics of the sex- and age-matched NAION patients and controls

\begin{tabular}{lccr}
\hline & NAION patients $(n=72)$ & Controls $(n=72)$ & $p$ value \\
\hline Men/women & $37(51.39 \%) / 35(48.61 \%)$ & $37(51.39 \%) / 35(48.61 \%)$ & \\
Age, years & $61.5^{\mathrm{a} \pm 10.95}$ & $61.5 \pm 10.95$ & 0.6162 \\
Age range, years & $35-82$ & $35-82$ & 0.0955 \\
Hypertension & $35(48.61 \%)$ & $32(44.44 \%)$ & 0.1350 \\
Dyslipidemia & $40(55.56 \%)$ & $30(41.67 \%)$ & $<0.0001$ \\
Diabetes mellitus & $17(23.61 \%)$ & $10(13.89 \%)$ & 0.0038 \\
History of heart/vascular $\quad$ & $4(5.56 \%)$ & 0.0059 \\
$\quad$ disease (total) & $25(34.72 \%)$ & $4(5.56 \%)$ & 0 \\
Heart disease & $16(22.22 \%)$ & 0 & \\
Cerebrovascular disease & $9(12.5 \%)$ & & \\
\hline
\end{tabular}

Values are presented as $n(\%)$, mean \pm standard deviation, or range. NAION, nonarteritic anterior ischemic optic neuropathy. ${ }^{\mathrm{a}}$ Indicates the average age at the first event. ${ }^{\mathrm{b}}$ Includes coronary heart disease and other pathologies that affect the heart such as arrhythmias, atrial fibrillation, and hypertensive heart disease.

arterial hypertension, dyslipidemia, and DM, as well as their clinical history of heart and vascular diseases.

NAION patients were diagnosed at Fernández-Vega Ophthalmological Institute by visual field examination, determination of nerve fiber layer thickness by optical coherence tomography, visual acuity, evoked potentials, examination of the papilla with identification of the edematous stages with or without peripapillary hemorrhages evolving to optic nerve atrophy, and papillary pallor. Finally, a complete neurological study including magnetic resonance imaging was carried out. Exclusion criteria for patients and controls included any history of ocular vascular disease such as retinal vein occlusion or retinal artery occlusion. The demographic characteristics of the NAION patients and control subjects are shown in Table 1.

Given that the clinical factors hypertension, dyslipidemia, DM, heart diseases (including coronary heart disease, arrhythmias, atrial fibrillation, and hypertensive heart disease), and cerebrovascular disease are influenced by sex and age, we performed our association study using 72 patients with NAION and 72 sex- and age-matched controls. The remaining 22 NAION subjects were excluded from this specific analysis owing to lack of appropriate controls to perform matching. When more than one control had the sex and age appropriate for matching with a specific NAION patient, the first one who came to the ophthalmologic examination was included. No characteristic or condition of the individuals other than sex or age was considered for pairing. The demographics and clinical characteristics of the sex- and age-matched NAION and control groups are reported in Table 2. 
Fernández-Vega et al.: MTHFR Polymorphisms and Nonarteritic Anterior Ischemic Optic Neuropathy

\section{Genotyping}

This study included the analysis of two SNPs located in the MTHFR gene, rs1801133 (C677T) and rs1801131 (A1298C). NAION patients $(n=94)$ were genotyped by DNA sequencing. All control individuals $(n=204)$ were genotyped by TaqMan assays. A subgroup of 25 randomly selected individuals among the 94 NAION patients was also genotyped by TaqMan assays in order to validate the results obtained by this technology.

Sequencing. Saliva sampling and genomic DNA purification were carried out using the DANASALIVA Sample Collection Kit (DANAGEN, Barcelona, Spain). Patients did not eat, drink, smoke, or chew gum at least $30 \mathrm{~min}$ before sampling. From 1 to $2 \mathrm{~mL}$ of saliva were collected in a tube, followed by addition of preservative solution and stirring. Extraction of the genomic DNA from each primary sample of saliva was carried out according to the recommendations of the DANAGEN manufactures protocols. Two PCR reactions designed to amplify the regions affected by the MTHFR variants (NM_005957) were carried out: c.677C $>$ T (exon 4) and c.1286A $>C$ (exon 7), using the genomic DNA from saliva. The DNA sequence was obtained through cyclic sequencing and capillary electrophoresis using the 3130XL Genetic Analyzer (Applied Biosystems Inc., Foster City, CA, USA) at the Instituto de Medicina Oncológica y Molecular de Asturias, Oviedo, Spain. The sequence obtained was compared with that deposited in Ensembl for the MTHFR gene (ENSG00000177000), corresponding to the chr1 coordinates: $11846660-11866115$ of the GRCh37 version of the human genome. The variants determined in each sample were identified following international nomenclature recommendations according to the produced effect in the nucleotide sequence (based on the reference sequence with RefSeq ID NM_005957) or protein (based on the reference sequence NP_005948).

TaqMan Technology. Peripheral blood samples from 25 patients diagnosed with NAION and all control individuals $(n=204)$ were collected in 6 -mL tubes coated with EDTA (Vacuette, Madrid, Spain). Samples were stored at $-20^{\circ} \mathrm{C}$ until DNA isolation. Genomic DNA was obtained from blood using a commercial DNA extraction kit (FlexiGene DNA Kit; Qiagen, Hilden, Germany) according to the manufacturer's protocol. Allelic discrimination of the SNPs was performed with TaqMan assays, C_1202883_20 (rs1801133, C677T) and C_850486_20 (rs1801131, A1298C), provided by the manufacturer (Applied Biosystems Inc.), in the 7500 Real Time PCR System (Applied Biosystems Inc.), at Fernández-Vega Ophthalmological Institute. All PCR amplifications were carried out with the thermal cycling conditions of $95^{\circ} \mathrm{C}$ for $10 \mathrm{~min}$, followed by 40 cycles at $92^{\circ} \mathrm{C}$ for $15 \mathrm{~s}$ and $60^{\circ} \mathrm{C}$ for $1 \mathrm{~min}$.

\section{Statistical Analysis}

The SNPs were assessed for Hardy-Weinberg equilibrium by a $\chi^{2}$ test in both groups (cases and controls) with the HaploView 4.0 software. The ages of the NAION patients and control subjects were compared using the unpaired $t$ test when the age variable was normally distributed in the compared groups or the Mann-Whitney test when the age variable was nonnormally distributed in any of the groups (GraphPad InStat 3.0, San Diego, CA, USA). The comparisons of the SNPs allelic frequencies as well as of the frequencies of the additionally considered potential risk factors, between groups, were performed using a standard $\chi^{2}$ test, with a $p$ value $<0.05$ considered statistically significant. Comparison of genotypic frequencies between the NAION and control groups was performed using a $\chi^{2}$ test (Pearson correction) with SPSS version 15.0 (IBM Corp, Armonk, NY, USA). Relative risk association was estimated by calculating odds ratios (ORs) along with $95 \%$ confidence intervals (CIs), using the methods described by Armitage et al. [49] and the tool PLINK (version 1.07). A linkage disequilibrium (LD) plot was generated with the HaploView 4.0 software and the LD block was defined according to the algorithm of Gabriel et al. [50]. Additionally, we used SPSS version 15.0 (IBM Corp.) to run a logistic regression analysis in order to control for potential confounders. 
Table 3. Allelic and genotypic association analysis

\begin{tabular}{|c|c|c|c|c|c|}
\hline \multicolumn{2}{|l|}{ SNP ID } & \multirow[t]{2}{*}{$\begin{array}{l}\text { NAION patients } \\
(n=94)\end{array}$} & \multirow[t]{2}{*}{$\begin{array}{l}\text { Controls } \\
(n=204)\end{array}$} & \multirow[t]{2}{*}{$p$ value } & \multirow[t]{2}{*}{ OR $(95 \% \mathrm{CI})$} \\
\hline & & & & & \\
\hline & $\mathrm{C}$ & 56.91 & 62.50 & & $0.91(0.72-1.14)$ \\
\hline & $\mathrm{T}$ & 43.09 & 37.50 & 0.1945 & $1.15(0.82-1.61)$ \\
\hline \multirow[t]{4}{*}{ Genotype } & $\mathrm{CC}$ & 31.91 & 40.69 & $0.6037^{\mathrm{a}}$ & $0.78(0.54-1.14)$ \\
\hline & CT & 50.00 & 43.63 & & $1.15(0.85-1.54)$ \\
\hline & TT & 18.09 & 15.69 & & $1.15(0.62-2.14)$ \\
\hline & total & 30/47/17 (CС/CT/ТT) & 83/89/32 (CС/СТ/ТT) & 0.3494 & \\
\hline \multicolumn{6}{|c|}{ rs1801131 A1298C } \\
\hline \multirow[t]{2}{*}{ Allele } & A & 71.28 & 69.61 & & $1.02(0.86-1.22)$ \\
\hline & $\mathrm{C}$ & 28.72 & 30.39 & 0.6791 & $0.94(0.62-1.45)$ \\
\hline \multirow[t]{4}{*}{ Genotype } & $\mathrm{AA}$ & 51.06 & 48.53 & $0.8224^{\mathrm{a}}$ & $1.05(0.80-1.39)$ \\
\hline & $\mathrm{AC}$ & 40.43 & 42.16 & & $0.96(0.69-1.33)$ \\
\hline & $\mathrm{CC}$ & 8.51 & 9.31 & & $0.91(0.38-2.22)$ \\
\hline & total & 48/38/8 (AA/AC/CC) & 99/86/19 (AA/AC/CC) & 0.9158 & \\
\hline
\end{tabular}

Statistical significance: $p<0.05$. Total indicates the general test of association in the 2-by-3 table of disease-bygenotype. CI, confidence interval; NAION, nonarteritic anterior ischemic optic neuropathy; OR, odds ratio; SNP, single nucleotide polymorphism. ${ }^{a} p$ values derived from comparison of the genotypic frequencies under the recessive model (TT vs. CT + CC at rs1801133 and CC vs. AC + AA at rs1801131).

\section{Results}

The studied cohort consisted of 94 patients diagnosed with NAION and 204 control subjects of a Spanish population. Allele and genotype frequencies of the MTHFR genetic variants (C677T and A1298C) were determined in cases and controls. The observed genotype frequencies of the two MTHFR SNPs were in Hardy-Weinberg equilibrium ( $p>0.05)$ in both NAION and control groups. The allelic and genotypic frequencies of the MTHFR variants obtained in the NAION group were not significantly different when compared with those of the control group (Table 3).

Pairwise LD analysis of the two SNPs showed that they were in strong LD (coefficient of $\mathrm{LD}=0.98$ ). Table 4 shows the nine theoretically possible genotypes resulting from the SNPs C677T and A1298C in NAION patients and control subjects. The C677T/A1298C genotype codifying the nonmutated MTHFR form (i.e., CC/AA) was significantly more frequent in control subjects (11.27\%) than in NAION patients (4.26\%), $p=0.0498$, with an OR of 0.38 (95\% CI: 0.13-1.06). The prevalence of the genotypes responsible of MTHFR mutated forms (i.e., CT/AC, CT/CC, CT/AA, TT/AA, TT/AC, TT/CC, CC/AC, and CC/CC) reached $95.74 \%$ in NAION patients and $88.73 \%$ in controls, without significant differences between groups.

According to Table 1, the distribution by sex did not show significant differences between groups, while the mean age of the controls ( $65.48 \pm 11.32$ years) was significantly higher than that of the NAION patients ( $57.39 \pm 16.54$ years). In addition to those comparisons, a variety of clinical risk factors, including hypertension, dyslipidemia, DM, and history of heart and vascular diseases, were assessed in a cohort of 72 patients with NAION and 72 sex- and agematched controls. As shown in Table 2, although the prevalence of all of the studied risk factors was higher in the NAION group compared with control subjects, the differences between both groups for hypertension, dyslipidemia, and DM were not statistically significant. 


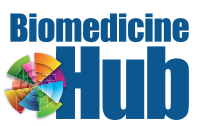

Table 4. Genotypic frequencies of NAION patients and controls

\begin{tabular}{l|l}
\hline Biomed Hub 2020;5:505431 \\
\hline DOI: 10.1159/000505431 & $\begin{array}{l}\text { @ 2020 The Author(s). Published by S. Karger AG, Basel } \\
\text { www.karger.com/bmh }\end{array}$ \\
\hline
\end{tabular}

Fernández-Vega et al:: MTHFR Polymorphisms and Nonarteritic Anterior Ischemic Optic Neuropathy

\begin{tabular}{lcll}
\hline $\begin{array}{l}\text { C677T } / \\
\text { A1298C }\end{array}$ & $\begin{array}{l}\text { NAION patients } \\
(n=94)\end{array}$ & $\begin{array}{l}\text { Controls } \\
(n=204)\end{array}$ & $p$ value \\
\hline TT/AA & $17(18.09 \%)$ & $31(15.20 \%)$ & ns \\
TT/AC & 0 & 0 & ns \\
TT/CC & 0 & 0 & ns \\
CT/AC & $20(21.28 \%)$ & $44(21.57 \%)$ & ns \\
CT/CC & 0 & 0 & ns \\
CT/AA & $27(28.72 \%)$ & $45(22.06 \%)$ & ns \\
CC/AC & $18(19.15 \%)$ & $41(20.10 \%)$ & ns \\
CC/CC & $8(8.51 \%)$ & $19(9.31 \%)$ & ns \\
CC/AA & $4(4.26 \%)$ & $23(11.27 \%)$ & 0.0498 \\
\hline
\end{tabular}

Values are presented as $n(\%)$. The risk allele is indicated in bold. AC, heterozygotes for A1298C including CT and TC subjects; CT, heterozygotes for C677T including CT and TC subjects; NAION, nonarteritic anterior ischemic optic neuropathy; ns, not significant.

In contrast, presence of any history of heart or vascular disease was found to be significantly associated with the occurrence of NAION $(p<0.0001)$. To discard possible interactions among risk factors, an additional multivariate logistic regression analysis was carried out. This analysis confirmed that both history of heart disease and vascular disease were independently associated with the prevalence of NAION.

\section{Discussion}

In this study we performed an association study of the MTHFR C677T and A1298C polymorphisms with NAION in a Spanish population. Additional cardiovascular risk factors for this pathology were also evaluated. In our population, the risk alleles of the genetic polymorphisms C677T and A1298C were not associated with a higher prevalence of NAION (Table 3). There were also no significant differences between the frequencies of the genotypes responsible of MTHFR mutated forms (i.e., CT/AC, CT/CC, CT/AA, TT/AA, TT/AC, TT/CC, CC/AC, and CC/CC) when comparing NAION patients (95.74\%) and control subjects (88.73\%) (Table 4).

According to previous publications, the mutant alleles of the MTHFR C677T and A1298C result in MTHFR protein with decreased enzymatic activity [48]. Therefore, individuals with the MTHFR mutant proteins may have high levels of plasma homocysteine, mainly if their folate levels are low $[45,46]$. Interestingly, although our results did not show a higher prevalence of NAION among individuals with MTHFR mutant proteins, a certain protective effect of wild-type protein was observed. Thus, the genotype CC/AA codifying the nonmutated MTHFR enzyme was significantly more frequent $(p=0.0498)$ in control subjects $(11.27 \%)$ than in NAION patients (4.26\%) (Table 4), with an OR of 0.38 . However, the CI obtained ( $95 \%$ CI: 0.13-1.06) includes the value 1 , and therefore it cannot be assured that the frequencies of both groups for the genotype CC/AA are significantly different.

The genetic association study was performed using a control group with an average age significantly higher than that of the NAION patients (65.48 vs. 57.39 years, $p<0.0001$ ) (Table 1). However, we must stress that among controls, individuals aged from 35 to 91 years were included. Considering that NAION is a late-onset disorder, some misclassification among the youngest individuals in the control group might be possible. Nevertheless, this risk is minimal considering the low annual incidence rate of this disease, estimated to range from 2.3 to 10.3 
cases per 100,000 people among persons aged $>50$ years [51, 52]. Even so, to minimize possible misclassification of some individuals included in the control group, we reanalyzed the data excluding all individuals aged $<60$ years from the control group. We therefore obtained a new control group composed of 144 individuals whose average age was 71.32 years and not statistically different from the NAION group. As expected, the results for both SNPs analyzed were similar to those obtained with the previous control group, in which the allele and genotype frequencies were not significantly different in NAION cases when compared to controls (data not shown). However, in this case, no significant differences between the NAION and control groups were obtained for the genotype CC/AA (4.26 vs. $11.11 \%, p=0.06$ ), which could be due to the smaller sample size.

Finally, to minimize any possible influence of sex and age on the genetic study, an additional association analysis of the MTHFR polymorphisms was carried out using the sex- and age-matched subgroups of NAION patients and control subjects described in Table 2 . This pairing reduced the likelihood that any observed differences between cases and controls might result from variances in the distribution by sex and age in both groups, although differences in additional unconsidered factors such as lifestyle or other systemic diseases could also have an influence. Similarly, the use of sex- and age-balanced subjects provided no association for any allele or genotype considered (data not shown). Moreover, no significant differences were obtained for the genotype CC/AA between these smaller NAION and control subgroups ( 5.56 vs. $9.52 \%, p=0.146)$. Overall, although the frequency of the CC/AA genotype was higher in control subjects than in NAION patients when compared nonbalanced and balanced case-controls for sex and age, our results evidenced again the scarce robust statistics of the protective effect of the wild-type MTHFR enzyme. Therefore, an additional study in a larger sample size of sex- and age-matched subgroups of NAION patients and controls may definitely confirm or rule out this effect.

Our results are consistent with those previously published in different populations around the world $[10,11,18,41]$, but controversy still remains because several studies showed a significant association of the 677TT genotype with NAION [36, 40]. Discrepancy between studies could be due to the great difficulty in the proper selection of patients. NAION is a multifactorial disease and very different factors contribute to its onset or development, which produces great heterogeneity in the group of patients under study.

The high presence of at least one of the considered risk variants in our population $(88.73 \%$ in the control group and $95.74 \%$ in the NAION group) is, with small variations, a common characteristic of Caucasian, Hispanic, and Asian populations. Interestingly, this frequency is much smaller in African black populations like those from Nigeria $(42.20 \%)$ or Gambia (30.97\%), in which, in addition, there is no individuals TT homozygous for C677T [53]. The racial influence on the genotypic frequencies of MTHFR variants could explain the higher incidence of NAION between Caucasians when compared with African black populations. However, Hispanics suffer also a lower incidence of NAION than Caucasians, while no significant differences in the MTHFR genotype frequencies are observed between these ethnic groups $[51,52]$. On the other hand, the NAION incidence in Asians (Korean population) has been reported as similar to that of Caucasians [54]. Interracial differences in the incidence or prevalence of NAION may reflect a genetic predisposition, but MTHFR variants do not seem to have a significant influence.

In addition to the genetic mutations discussed, our study also included some clinical risk factors classically associated with NAION, such as hypertension, dyslipidemia, DM, heart diseases (i.e., coronary heart disease, arrhythmias, atrial fibrillation, and hypertensive heart disease), and cerebrovascular disease (Table 2). To minimize the influence of sex and age on these conditions, we performed the association analysis using sex-andage-matched subgroups of patients with NAION and controls. This pairing reduced the likelihood that any observed 
Fernández-Vega et al.: MTHFR Polymorphisms and Nonarteritic Anterior Ischemic Optic Neuropathy

Table 5. Association of potential clinical risk factors with NAION in case-control studies published to date

\begin{tabular}{|c|c|c|c|c|c|c|}
\hline $\begin{array}{l}\text { Study } \\
\text { (first } \\
\text { author) }\end{array}$ & $\begin{array}{l}\text { Cases/ } \\
\text { controls }^{\mathrm{a}}\end{array}$ & $\begin{array}{l}\text { Diabetes } \\
\text { mellitus }\end{array}$ & $\begin{array}{l}\text { Systemic } \\
\text { hypertension }\end{array}$ & $\begin{array}{l}\text { Dyslipidemia/ } \\
\text { hypercholesterolemia }\end{array}$ & $\begin{array}{l}\text { Ischemic } \\
\text { heart disease }\end{array}$ & $\begin{array}{l}\text { Cerebrovascular } \\
\text { disease }\end{array}$ \\
\hline Present study & $72 / 72$ & $\begin{array}{l}\text { no } \\
\text { association }\end{array}$ & $\begin{array}{l}\text { no } \\
\text { association }\end{array}$ & $\begin{array}{l}\text { no } \\
\text { association }\end{array}$ & $\begin{array}{l}p=0.1898 \\
p=0.0038^{\mathrm{b}}\end{array}$ & $p=0.0059$ \\
\hline Talks [55], 1995 & $41 / 41$ & $\begin{array}{l}\text { no } \\
\text { association }\end{array}$ & $\begin{array}{l}\text { no } \\
\text { association }\end{array}$ & $p<0.05$ & $\begin{array}{l}\text { no } \\
\text { association }\end{array}$ & $p<0.001$ \\
\hline $\begin{array}{l}\text { Jacobson [9], } \\
1997\end{array}$ & $51 / 51$ & $p=0.01$ & $\begin{array}{l}\text { no } \\
\text { association }\end{array}$ & $\begin{array}{l}\text { no } \\
\text { association }\end{array}$ & $\begin{array}{l}\text { no } \\
\text { association }\end{array}$ & NA \\
\hline $\begin{array}{l}\text { Salomon [10], } \\
1999\end{array}$ & $61 / 90$ & $p=0.034$ & $\begin{array}{l}\text { no } \\
\text { association }\end{array}$ & $p=0.011$ & $p=0.007$ & $\begin{array}{l}\text { no } \\
\text { association }\end{array}$ \\
\hline $\begin{array}{l}\text { Weger [11], } \\
2001\end{array}$ & $59 / 59$ & $p=0.0263$ & $p=0.0245$ & NA & $\begin{array}{l}\text { no } \\
\text { association }\end{array}$ & $\begin{array}{l}\text { no } \\
\text { association }\end{array}$ \\
\hline $\begin{array}{l}\text { Deramo [12], } \\
2003\end{array}$ & $37 / 74$ & $p=0.027$ & $\begin{array}{l}\text { no } \\
\text { association }\end{array}$ & $p=0.036$ & NA & NA \\
\hline $\begin{array}{l}\text { Nagy [19], } \\
2006\end{array}$ & $37 / 81$ & $\begin{array}{l}\text { no } \\
\text { association }\end{array}$ & $\begin{array}{l}\text { no } \\
\text { association }\end{array}$ & $p=0.012$ & $\begin{array}{l}\text { no } \\
\text { association }\end{array}$ & NA \\
\hline $\begin{array}{l}\text { Hayreh [13], } \\
2007\end{array}$ & $624 /{ }^{c}$ & $p<0.0001$ & $p<0.0001$ & NA & $p<0.0001$ & $p<0.0001$ \\
\hline $\begin{array}{l}\text { Giambene [18], } \\
2009\end{array}$ & $85 / 107$ & $\begin{array}{l}\text { no } \\
\text { association }\end{array}$ & $p<0.0001$ & $p=0.01$ & NA & NA \\
\hline $\begin{array}{l}\text { Felekis [40], } \\
2010\end{array}$ & $77 / 60$ & $\begin{array}{l}\text { no } \\
\text { association }\end{array}$ & $\begin{array}{l}\text { no } \\
\text { association }\end{array}$ & $\begin{array}{l}\text { no } \\
\text { association }\end{array}$ & NA & NA \\
\hline $\begin{array}{l}\text { Kim [15], } \\
2017\end{array}$ & $45 / 45$ & $p=0.020$ & $\begin{array}{l}\text { no } \\
\text { association }\end{array}$ & $p=0.001$ & NA & NA \\
\hline
\end{tabular}

NA, data not available; NAION, nonarteritic anterior ischemic optic neuropathy. ${ }^{a}$ Age- and sex-matched. ${ }^{b}$ Includes coronary or ischemic heart disease and other pathologies that affect the heart such as arrhythmias, atrial fibrillation, and hypertensive heart disease. ${ }^{c}$ Race-, sex-, age-, and period-matched subgroup of the US population.

differences for these parameters between cases and controls resulted from variances in the distribution by sex and age in both groups. However, this possibility is not entirely discarded because differences in additional unconsidered factors such as lifestyle or other systemic diseases could have influence.

Although the considered clinical factors were more frequently found among NAION patients than controls, only clinical history of heart disease $(p=0.0038)$ and cerebrovascular disease $(p=0.0058)$ were most prevalent in NAION patients, with statistically significant differences. The additional clinical factors evaluated (i.e., hypertension, DM, and dyslipidemia) were not associated with a higher risk of NAION in our population (Table 2). Table 5 shows a comprehensive summary of the published case-control studies concerning the association of these clinical factors with NAION to date. As can be observed, there is no agreement on the association of any of these clinical variables with NAION. The lack of consensus could be due to the great complexity and heterogeneity of the disease, influenced by multiple variables, hindering the selection of a homogenous group of patients and appropriate controls. However, the fact that at least several studies have shown association of a specific genetic or 
clinical factor with NAION suggests that its combination with other potential risk factors may contribute to a higher predisposition to this ocular disease. The combination of systemic and local risk factors, which can be different in each patient, could be responsible for the pathology onset. Although the precise mechanism for the development of NAION is uncertain, it is widely accepted that the disease is caused by a decrease in blood flow to the ONH. One of the main factors causing insufficient blood flow through the PCAs to the ONH seems to be nocturnal arterial hypotension during sleep in susceptible patients with the additional risk factors discussed.

The MTHFR mutations analyzed in this study did not have a significant effect on the occurrence of NAION in our population. However, the genotype CC/AA codifying the nonmutated MTHFR enzyme showed higher frequency in control subjects than in NAION patients, which may be related to a protective effect of the wild-type protein. Interestingly, the risk variants of the MTHFR gene are highly prevalent in most populations over the world, with the exception of African black populations, suggesting a racial influence. Plasma homocysteine levels may be influenced by factors different than the variants of this gene. Nutritional deficiencies such as low levels of folate or vitamin B12 are important determinants of these levels. Thus, analysis of the serum concentrations of homocysteine, folate, and vitamin B12 could help identify subgroups of patients with NAION in whom the presence of MTHFR mutations could be a significant risk factors. Finally, although additional clinical factors including hypertension, DM, and dyslipidemia were not associated with a higher risk of NAION in our Spanish population, the combination of others systemic and local risk factor, such as heart and cerebrovascular disease, may play a role in the onset of the pathology.

\section{Acknowledgement}

B. Fernández-Vega and H. González-Iglesias thank Fabiola Fernández Andrés and Adrián González-Fernández for their inestimable help.

\section{Statement of Ethics}

The study adhered to the tenets of the Declaration of Helsinki on Biomedical Research Involving Human Subjects and was approved by the Clinical Research Ethics Committee at Principality of Asturias, Oviedo, Spain. All participants signed an informed consent form.

\section{Disclosure Statement}

The authors have no conflicts of interest to declare.

\section{Funding Sources}

The Instituto Oftalmológico Fernández-Vega and Fundación de Investigación Oftalmológica acknowledge support from the Fundación Rafael del Pino (www.frdelpino.es) through the Cátedra Rafael del Pino. 
Fernández-Vega et al.: MTHFR Polymorphisms and Nonarteritic Anterior Ischemic Optic Neuropathy

\section{Author Contributions}

Conceptualization: B. Fernández-Vega, L. Álvarez, J.A. Vega, H. González-Iglesias. Formal analysis: B. Fernández-Vega, L. Álvarez, M. García, E. Artime. Funding acquisition: J.A. Vega, H. González-Iglesias. Data collection: B. Fernández-Vega, L. Álvarez. Methodology: B. FernándezVega, L. Álvarez, J. Nicieza. Project administration: J.A. Vega, H. González-Iglesias. Resources: M. Diñeiro Soto, J. Nicieza, H. González-Iglesias. Supervision: J.A. Vega, H. González-Iglesias. Validation: M. García, M. Diñeiro Soto. Visualization: B. Fernández-Vega, L. Álvarez, M. García. Writing of the original draft: B. Fernández-Vega, L. Álvarez. Manuscript review and editing: J. Nicieza, J.A. Vega, H. González-Iglesias.

\section{References}

1 Hayreh SS. Ischemic optic neuropathy. Prog Retin Eye Res. 2009 Jan;28(1):34-62.

2 Hayreh SS. Anterior ischaemic optic neuropathy. I. Terminology and pathogenesis. Br J Ophthalmol. 1974 Dec; 58(12):955-63.

3 Hayreh SS. Posterior ischemic optic neuropathy. Ophthalmologica. 1981;182(1):29-41.

4 Hayreh SS. Anterior ischaemic optic neuropathy. Differentiation of arteritic from non-arteritic type and its management. Eye (Lond). 1990;4(Pt 1):25-41.

5 Newman JN, Dickersin K, Kaufman D, Kelman S, Scherer R. Characteristics of patients with nonarteritic anterior ischemic optic neuropathy eligible for the Ischemic Optic Neuropathy Decompression Trial. Arch Ophthalmol. 1996 Nov;114(11):1366-74.

6 Repka MX, Savino PJ, Schatz NJ, Sergott RC. Clinical profile and long-term implications of anterior ischemic optic neuropathy. Am J Ophthalmol. 1983 Oct;96(4):478-83.

7 Buono LM, Foroozan R, Sergott RC, Savino PJ. Nonarteritic anterior ischemic optic neuropathy. Curr Opin Ophthalmol. 2002 Dec;13(6):357-61.

8 Hayreh SS, Joos KM, Podhajsky PA, Long CR. Systemic diseases associated with nonarteritic anterior ischemic optic neuropathy. Am J Ophthalmol. 1994 Dec;118(6):766-80.

9 Jacobson DM, Vierkant RA, Belongia EA. Nonarteritic anterior ischemic optic neuropathy. A case-control study of potential risk factors. Arch Ophthalmol. 1997 Nov;115(11):1403-7.

10 Salomon O, Huna-Baron R, Kurtz S, Steinberg DM, Moisseiev J, Rosenberg N, et al. Analysis of prothrombotic and vascular risk factors in patients with nonarteritic anterior ischemic optic neuropathy. Ophthalmology. 1999 Apr;106(4):739-42.

11 Weger M, Stanger O, Deutschmann H, Simon M, Renner W, Schmut O, et al. Hyperhomocyst(e)inaemia, but not MTHFR C677T mutation, as a risk factor for non-arteritic ischaemic optic neuropathy. Br J Ophthalmol. 2001 Jul;85(7):803-6.

12 Deramo VA, Sergott RC, Augsburger JJ, Foroozan R, Savino PJ, Leone A. Ischemic optic neuropathy as the first manifestation of elevated cholesterol levels in young patients. Ophthalmology. 2003 May;110(5):1041-6.

13 Hayreh SS, Jonas JB, Zimmerman MB. Nonarteritic anterior ischemic optic neuropathy and tobacco smoking. Ophthalmology. 2007 Apr;114(4):804-9.

14 Hayreh SS, Zimmerman MB. Nonarteritic anterior ischemic optic neuropathy: clinical characteristics in diabetic patients versus nondiabetic patients. Ophthalmology. 2008 Oct;115(10):1818-25.

15 Kim DH, Shin GR, Choi YJ. Risk Factors for Non-arteritic Anterior Ischaemic Optic Neuropathy in a Korean Population. Neuroophthalmology. 2017 Jan;41(2):68-75.

16 Hayreh SS, Zimmerman MB, Podhajsky P, Alward WL. Nocturnal arterial hypotension and its role in optic nerve head and ocular ischemic disorders. Am J Ophthalmol. 1994 May;117(5):603-24.

17 Hayreh SS, Podhajsky P, Zimmerman MB. Role of nocturnal arterial hypotension in optic nerve head ischemic disorders. Ophthalmologica. 1999;213(2):76-96.

18 Giambene B, Sodi A, Sofi F, Marcucci R, Fedi S, Abbate R, et al. Evaluation of traditional and emerging cardiovascular risk factors in patients with non-arteritic anterior ischemic optic neuropathy: a case-control study. Graefes Arch Clin Exp Ophthalmol. 2009 May;247(5):693-7.

19 Nagy V, Steiber Z, Takacs L, Vereb G, Berta A, Bereczky Z, et al. Thrombophilic screening for nonarteritic anterior ischemic optic neuropathy. Graefes Arch Clin Exp Ophthalmol. 2006 Jan;244(1):3-8.

20 Hayreh SS. Anterior ischemic optic neuropathy. VIII. Clinical features and pathogenesis of post-hemorrhagic amaurosis. Ophthalmology. 1987 Nov;94(11):1488-502.

21 Hayreh SS. Acute ischemic disorders of the optic nerve: pathogenesis, clinical manifestations and management. Ophthalmol Clin North Am. 1996;9:407-42.

22 Mojon DS, Hedges TR 3rd, Ehrenberg B, Karam EZ, Goldblum D, Abou-Chebl A, et al. Association between sleep apnea syndrome and nonarteritic anterior ischemic optic neuropathy. Arch Ophthalmol. 2002 May; 120(5): 601-5. 
Fernández-Vega et al.: MTHFR Polymorphisms and Nonarteritic Anterior Ischemic Optic Neuropathy

23 Behbehani R, Mathews MK, Sergott RC, Savino PJ. Nonarteritic anterior ischemic optic neuropathy in patients with sleep apnea while being treated with continuous positive airway pressure. Am J Ophthalmol. 2005 Mar; 139(3):518-21.

24 Palombi K, Renard E, Levy P, Chiquet C, Deschaux C, Romanet JP, et al. Non-arteritic anterior ischaemic optic neuropathy is nearly systematically associated with obstructive sleep apnoea. Br J Ophthalmol. 2006 Jul; 90(7):879-82.

25 Hayreh SS. Non-arteritic anterior ischemic optic neuropathy versus cerebral ischemic stroke. Graefes Arch Clin Exp Ophthalmol. 2012 Sep;250(9):1255-60.

26 Lee AG, Newman NJ. Erectile dysfunction drugs and nonarteritic anterior ischemic optic neuropathy. Am J Ophthalmol. 2005 Oct;140(4):707-8.

27 Pomeranz HD, Smith KH, Hart WM Jr, Egan RA. Sildenafil-associated nonarteritic anterior ischemic optic neuropathy. Ophthalmology. 2002 Mar;109(3):584-7.

28 Pomeranz HD, Bhavsar AR. Nonarteritic ischemic optic neuropathy developing soon after use of sildenafil (Viagra): a report of seven new cases. J Neuroophthalmol. 2005 Mar;25(1):9-13.

29 Beck RW, Servais GE, Hayreh SS. Anterior ischemic optic neuropathy. IX. Cup-to-disc ratio and its role in pathogenesis. Ophthalmology. 1987 Nov;94(11):1503-8.

30 Hayreh SS. Blood flow in the optic nerve head and factors that may influence it. Prog Retin Eye Res. 2001 Sep; 20(5):595-624.

31 Hayreh SS, Podhajsky PA, Zimmerman B. Nonarteritic anterior ischemic optic neuropathy: time of onset of visual loss. Am J Ophthalmol. 1997 Nov;124(5):641-7.

32 Hayreh SS, Zimmerman MB, Podhajsky P, Alward WL. Nonarteritic anterior ischemic optic neuropathy: role of nocturnal arterial hypotension. Arch Ophthalmol. 1997 Jul;115(7):942-5.

33 Mathews MK. Nonarteritic anterior ischemic optic neuropathy. Curr Opin Ophthalmol. 2005 Dec;16(6):341-5.

34 Acheson JF, Sanders MD. Coagulation abnormalities in ischaemic optic neuropathy. Eye (Lond). 1994;8(Pt 1): 89-92.

35 Pianka P, Almog Y, Man O, Goldstein M, Sela BA, Loewenstein A. Hyperhomocysteinemia in patients with nonarteritic anterior ischemic optic neuropathy, central retinal artery occlusion, and central retinal vein occlusion. Ophthalmology. 2000 Aug; 107(8):1588-92.

36 Glueck CJ, Wang P, Bell H, Rangaraj V, Goldenberg N. Nonarteritic anterior ischemic optic neuropathy: associations with homozygosity for the C677T methylenetetrahydrofolate reductase mutation. J Lab Clin Med. 2004 Mar;143(3):184-92.

37 Van Cott EM, Laposata M, Hartnett ME. Prothrombin gene mutation G20210A, homocysteine, antiphospholipid antibodies and other hypercoagulable states in ocular thrombosis. Blood Coagul Fibrinolysis. 2004 Jul; 15(5):393-7.

38 Stanger O, Weger M, Obeid R, Temmel W, Meinitzer A, Steinbrugger I, et al. Impairment of homocysteine metabolism in patients with retinal vascular occlusion and non-arteritic ischemic optic neuropathy. Clin Chem Lab Med. 2005;43(10):1020-5.

39 Kuhli-Hattenbach C, Scharrer I, Lüchtenberg M, Hattenbach LO. Selective thrombophilia screening of patients with nonarteritic anterior ischemic optic neuropathy. Graefes Arch Clin Exp Ophthalmol. 2009 Apr;247(4): 485-90.

40 Felekis T, Kolaitis NI, Kitsos G, Vartholomatos G, Bourantas KL, Asproudis I. Thrombophilic risk factors in the pathogenesis of non-arteritic anterior ischemic optic neuropathy patients. Graefes Arch Clin Exp Ophthalmol. 2010 Jun;248(6):877-84.

41 Biousse V, Kerrison JB, Newman NJ, Kawasaki A, Purvin V, Burgett R. Is non-arteritic anterior ischaemic optic neuropathy related to homocysteine? Br J Ophthalmol. 2000 May;84(5):555.

42 Klerk M, Verhoef P, Clarke R, Blom HJ, Kok FJ, Schouten EG; MTHFR Studies Collaboration Group. MTHFR 677C->T polymorphism and risk of coronary heart disease: a meta-analysis. JAMA. 2002 Oct; 288(16):202331.

43 Varga EA, Sturm AC, Misita CP, Moll S. Cardiology patient pages. Homocysteine and MTHFR mutations: relation to thrombosis and coronary artery disease. Circulation. 2005 May;111(19):e289-93.

44 Kawasaki A, Purvin VA, Burgett RA. Hyperhomocysteinaemia in young patients with non-arteritic anterior ischaemic optic neuropathy. Br J Ophthalmol. 1999 Nov;83(11):1287-90.

45 Jacques PF, Bostom AG, Williams RR, Ellison RC, Eckfeldt JH, Rosenberg IH, et al. Relation between folate status, a common mutation in methylenetetrahydrofolate reductase, and plasma homocysteine concentrations. Circulation. 1996 Jan;93(1):7-9.

46 Frosst P, Blom HJ, Milos R, Goyette P, Sheppard CA, Matthews RG, et al. A candidate genetic risk factor for vascular disease: a common mutation in methylenetetrahydrofolate reductase. Nat Genet. 1995 May; 10(1): $111-3$.

47 Weisberg I, Tran P, Christensen B, Sibani S, Rozen R. A second genetic polymorphism in methylenetetrahydrofolate reductase (MTHFR) associated with decreased enzyme activity. Mol Genet Metab. 1998 Jul;64(3):169-72.

48 Rozen R. Genetic predisposition to hyperhomocysteinemia: deficiency of methylenetetrahydrofolate reductase (MTHFR). Thromb Haemost. 1997 Jul;78(1):523-6.

49 Armitage P, Berry G, Matthews J. Statistical methods in medical research. Oxford: Blackwell Science; 2002.

50 Gabriel SB, Schaffner SF, Nguyen H, Moore JM, Roy J, Blumenstiel B, et al. The structure of haplotype blocks in the human genome. Science. 2002 Jun;296(5576):2225-9. 
51 Johnson LN, Arnold AC. Incidence of nonarteritic and arteritic anterior ischemic optic neuropathy. Populationbased study in the state of Missouri and Los Angeles County, California. J Neuroophthalmol. 1994 Mar;14(1): $38-44$.

52 Hattenhauer MG, Leavitt JA, Hodge DO, Grill R, Gray DT. Incidence of nonarteritic anterior ischemic optic neuropathy. Am J Ophthalmol. 1997 Jan;123(1):103-7.

53 Fernández-Vega B, Álvarez L, García M, Artime E, González Fernández A, Fernández-Vega C, et al. Association study of high-frequency variants of MTHFR gene with retinal vein occlusion in a Spanish population. Ophthalmic Genet. 2019 Aug;40(4):342-9.

54 Lee JY, Park KA, Oh SY. Prevalence and incidence of non-arteritic anterior ischaemic optic neuropathy in South Korea: a nationwide population-based study. Br J Ophthalmol. 2018 Jul;102(7):936-41.

55 Talks SJ, Chong NH, Gibson JM, Dodson PM. Fibrinogen, cholesterol and smoking as risk factors for non-arteritic anterior ischaemic optic neuropathy. Eye (Lond). 1995;9(Pt 1):85-8. 